\title{
Induction Motor Direct Torque Control with Synchronous PWM
}

\author{
Alessandro Benevieri, Gianmarco Maragliano, Mario Marchesoni * $\mathbb{D}$, Massimiliano Passalacqua (D) \\ and Luis Vaccaro (D)
}

check for

updates

Citation: Benevieri, A.; Maragliano, G.; Marchesoni, M.; Passalacqua, M.; Vaccaro, L. Induction Motor Direct Torque Control with Synchronous PWM. Energies 2021, 14, 5025. https://doi.org/10.3390/en14165025

Academic Editor: Chunhua Liu

Received: 20 July 2021

Accepted: 10 August 2021

Published: 16 August 2021

Publisher's Note: MDPI stays neutral with regard to jurisdictional claims in published maps and institutional affiliations.

Copyright: (c) 2021 by the authors. Licensee MDPI, Basel, Switzerland. This article is an open access article distributed under the terms and conditions of the Creative Commons Attribution (CC BY) license (https:/ / creativecommons.org/licenses/by/ $4.0 /)$.
Department of Electrical, Electronic, Tlc Engineering and Naval Architecture (DITEN), University of Genova, via all'Opera Pia 11a, 16145 Genova, Italy; alessandro.benevieri95@gmail.com (A.B.); 53899@unige.it (G.M.); massimiliano.passalacqua@edu.unige.it (M.P.); luis.vaccaro@unige.it (L.V.)

* Correspondence: marchesoni@unige.it

\begin{abstract}
A novel induction motor direct torque control (DTC) algorithm with synchronous modulation is presented. Compared to the traditional DTC method, whose main drawback is the presence of low-frequency torque harmonics (sub-harmonics), in the proposed method, the PWM switching frequency is imposed to be an integer multiple of the main supply frequency. This is achieved by continuously adjusting the PWM switching period to significantly reduce low-frequency harmonics. The devised algorithm has been tested on an inverter-fed induction motor drive system, and the obtained results show an important reduction of the sub-harmonic spectral content of the developed torque with respect to a conventional direct torque control while maintaining at the same time a high dynamic response.
\end{abstract}

Keywords: direct torque control; synchronous PWM; induction motor drive

\section{Introduction}

In the middle of the 1980s, the basis for a novel induction motor control technique was introduced by Depenbrock [1] and Takahashi and Noguchi [2]. The new strategy, named Direct Torque Control (DTC), whose basic scheme is represented in Figure 1, is based on the direct, fast determination of the control quantities, typically the supply stator voltages, by means of two hysteresis comparators and a switching table, upon the knowledge of reference and estimated magnetic flux and torque. The DTC scheme is very well suited to the structure of modern electronic converters and makes possible the control of high-power motors with related simplicity and high dynamic performance.

Since its introduction, the basic DTC scheme has evolved, aiming to improve:

- transient behaviour, with particular reference to the motor start-up and to the conditions of maximum torque development;

- torque ripple;

- behaviour around zero speed, e.g., performance during starting from a standstill;

- $\quad$ switching period uncertainty;

- $\quad$ acoustic noise generated by power electronics supply.

Many contributions can be found in the technical literature, where some of these aspects have been faced. For instance, in starting conditions, the classical DTC selects frequently the zero voltage vectors: this can lead to not complete exploitation of the magnetic circuit, hence limiting the developed torque. A solution to this problem is proposed in $[3,4]$, where a modified switching table is devised to fully exploit the vector set depending on the operating conditions; in the studies [5-9], predictive techniques are considered, while in [10-15], other solutions are indicated.

A method for reducing the torque ripple is described in [16,17]: the switching period is divided into equal sub-periods, with consequent more space voltage vectors availability. The additional resolution is obtained at the cost of more levels required in the hysteresis comparators and of a more accurate switching table, which requires also the motor speed 
as an additional input. In refs. [18,19], other methods are introduced, using a three-level voltage-source inverter. An improved scheme of torque tracking control is proposed in [20] with the aim of reducing the torque ripple.

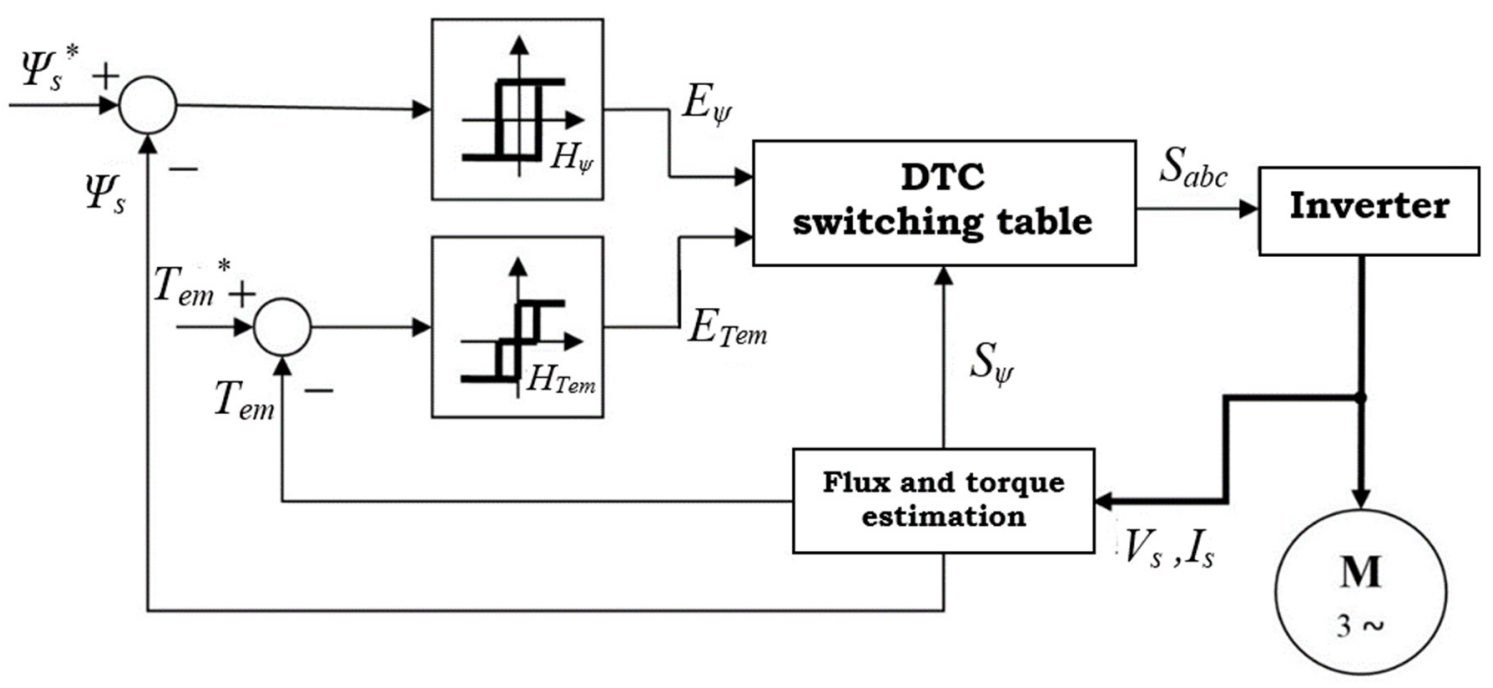

Figure 1. The DTC basic scheme. $\psi_{s}{ }^{*}$ and $T_{e m}{ }^{*}$ are the reference flux and the reference electromagnetic torque.

In the basic DTC scheme, the switching frequency of the inverter power semiconductors is determined by the width of the two hysteresis comparators bands and by the load and speed conditions. The uncertainty of the switching period can lead to current and torque distortion due to irregular voltage vector switching and multiple switching involving different inverter branches. In [21], a drive system with SVPWM with a fixed switching period is described. The stator voltage references are calculated in a dead-beat fashion upon the knowledge of the flux and torque commands, transient inductance and back EMF estimation.

It is well known that, in PWM modulation, a very desirable condition is achieved when the frequency of the carrier signal assumes integer multiple values of the modulating frequency value: when this occurs, the spectrum of the modulated signal is characterized by its best frequency spectrum in terms of sub-harmonics components. This harmonic effect, usually negligible when the carrier frequency is much higher than the modulating frequency, becomes more and more important when the magnitude order of the two frequencies is comparable. This is, for example, the case of an inverter-fed high power induction motor, where the carrier frequency, due to the high-power semiconductors constraints, is limited to a few hundred Hz.

The ratio between carrier frequency fs and modulation frequency $\mathrm{fm}$ is defined by the modulation ratio $\mathrm{mf}$ :

$$
\mathrm{mf}=\mathrm{fs} / \mathrm{fm}
$$

When $\mathrm{mf}$ does not assume integer values, there is the possibility of the appearance of sub-harmonic frequency components in the developed torque, typically at frequency values less than about a hundred Hz. These frequency components cannot be sufficiently filtered by the low-pass nature of the motor structure and can be a source of troubles such as mechanical chatter and resonance. In modern drives, the synchronicity condition, represented by a $\mathrm{mf}$ integer value, is obtained by establishing a relation between $\mathrm{fs}$, the PWM switching frequency, and $\mathrm{fm}$, the supply fundamental frequency, like that depicted in Figure 2, where $\mathrm{fb}$ is the base frequency of the motor. In Figure 2, it is possible to observe two operating regions: a first region, where fm frequency assumes values such that $\mathrm{fm} / \mathrm{fb}<\mathrm{f}^{\prime}$, is characterized by an asynchronous operation (here $\mathrm{fs}>>\mathrm{fm}$ : the condition of integer $\mathrm{mf}$ loses its importance), in the second region, with increasing fm values, such that 
$\mathrm{fm} / \mathrm{fb}>\mathrm{f}^{\prime}$, there are some different operating sub-regions characterized by the synchronous condition, each corresponding to a particular integer $\mathrm{mf}, \mathrm{i}$ value.

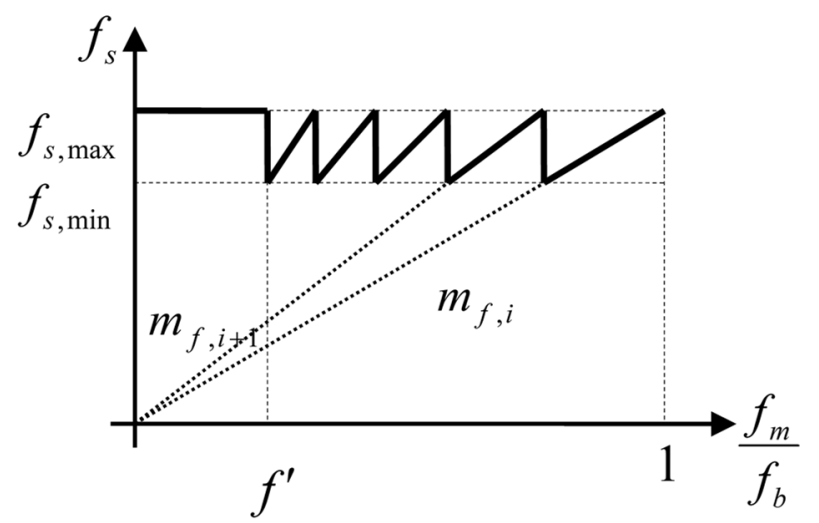

Figure 2. Carrier frequency and modulating frequency relation.

None of the evolutions $[3,21]$ of the basic DTC scheme makes reference to the synchronicity condition (1). In the present paper, a direct torque control algorithm is developed, which imposes, over the single switching period, an integer ratio between the switching frequency fs and the fundamental supply frequency $\mathrm{fm}$, in order to improve the sub-harmonic frequency content of the developed torque and so reducing the risk of the above-mentioned mechanical troubles, originated by the presence of significant low-frequency components. Some simulations have been carried out, and the results will be presented, emphasizing, in particular, the performance of the novel control scheme with respect to a traditional and basic DTC scheme.

\section{Synchronous Direct Torque Control Theory}

The electromagnetic torque $T_{e m}$ in an induction motor, in a two-phase $d-q$ reference frame [22], is expressed by Equation (2):

$$
T_{e m}=P\left(\psi_{s d} i_{s q}-\psi_{s q} i_{s d}\right)
$$

where $P$ is the pole pairs number, $\vec{\psi}_{s}$ is the stator flux, and $\overrightarrow{i_{s}}$ is the stator current. Differentiating with respect to time, the torque variation $d T_{e m}$ in $d t$ is given by Equation (3):

$$
d T_{e m}=P\left(d \psi_{s d} i_{s q}+\psi_{s d} d i_{s q}-d \psi_{s q} i_{s d}-\psi_{s q} d i_{s d}\right)
$$

where $d \overrightarrow{\psi_{s}}$ and $d \overrightarrow{i_{s}}$ are the flux and current variations. An equivalent circuit, in the stationary reference frame, of an inverter-driven induction machine is shown in Figure 3.

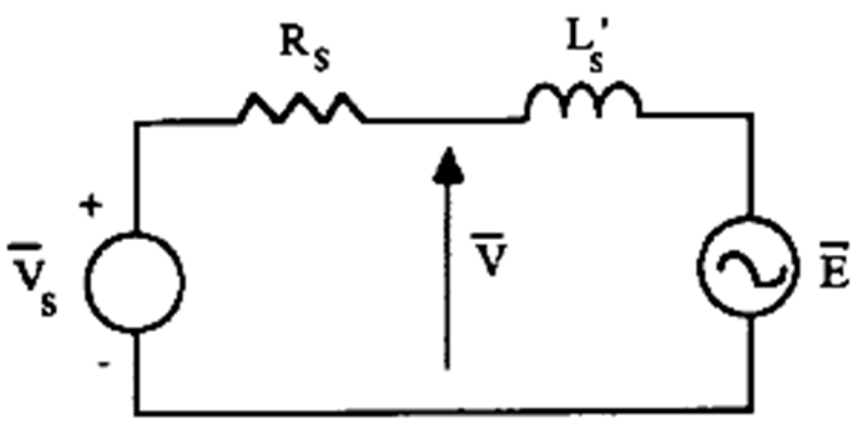

Figure 3. Equivalent circuit of inverter-driven induction motor. 
Considering a time period $T_{S}$ that is sufficiently small with respect to the time constant of the circuit, the change in current $\Delta \overrightarrow{i_{s}}$ can be assumed to be linear and given by Equation (4):

$$
\Delta \overrightarrow{i_{s}}=\frac{\vec{V}-\vec{E}}{L_{s}^{\prime}} T_{s}
$$

where $\vec{V}=V_{s d}+j V_{s q}$ is the inductance stator voltage, $L_{s}^{\prime}$ the transient inductance, and $\vec{E}=E_{s d}+j E_{s q}$ the back EMF behind $L_{s}^{\prime}$. The back EMF voltage can be estimated from the stator flux and current, that is, from the equivalent circuit, as shown in Equation (5).

$$
\overrightarrow{E_{s}}=\vec{V}_{s}-R_{s} \overrightarrow{i_{s}}-\frac{d}{d t}\left(L_{s}^{\prime} \overrightarrow{i_{s}}\right)=\frac{d}{d t}\left(\vec{\psi}_{s}-L_{s}^{\prime} \overrightarrow{i_{s}}\right)
$$

The stator flux variation in Equation (3) is due to the applied command stator voltage $\vec{V}_{S}$ minus the stator resistance drop $R_{s} \overrightarrow{i_{S}}$ and is given by Equation (6).

$$
\Delta \overrightarrow{\psi_{s}}=\left(\vec{V}_{s}-R_{s} \vec{i}_{s}\right) T_{s}
$$

Substituting the current (4) and flux (6) changes into Equation (3) and collecting terms, the torque change $\Delta T_{e m}$ over $T_{S}$ can be expressed by Equation (7).

$$
\frac{L_{s}^{\prime}}{P} \Delta T_{e m}-L_{s}^{\prime}\left(\Delta \psi_{s d} i_{s q}-\Delta \psi_{s q} i_{s d}\right)-\left(\psi_{s d} \Delta \psi_{s q}-\psi_{s q} \Delta \psi_{s d}\right)=\left(\psi_{s q} E_{d}-\psi_{s d} E_{q}\right) T_{s}
$$

The torque variation over the period $T_{S}$ can then be predicted from the stator voltage and current and the estimated back EMF by the application of a stator voltage command $\vec{V}_{S}$ such as to satisfy Equations (6) and (7). The flux variation in Equation (6) must be as such to maintain the magnitude of the flux vector itself around its reference, usually the machine rated value. The flux change over the period $T_{S}$ is the difference between vector values, as in Equation (8).

$$
\Delta \vec{\psi}_{s}=\overrightarrow{\psi_{s}^{*}}-\overrightarrow{\psi_{s}}
$$

$\vec{\psi}_{s}$ and $\overrightarrow{\psi_{s}^{*}}$ represent the flux vector, respectively, at the beginning and end of the period. Given the initial values of the current $\overrightarrow{i_{s}}$, stator flux $\vec{\psi}_{s}$, and back EMF $\vec{E}$, Equation (7) represents a line in the plane $\psi_{s d^{\prime}}^{*} \psi_{s q}^{*}$, which is observable rewriting the equation itself in the form of Equation (9):

$$
\psi_{s q}^{*}=a \psi_{s d}^{*}+\left(\psi_{s q}-a \psi_{s d}+b\right)
$$

with $a$ and $b$ given by Equation (10):

$$
a=\frac{\left(L_{s}^{\prime} i_{s q}-\psi_{s q}\right)}{\left(L_{s}^{\prime} i_{s d}-\psi_{s d}\right)}
$$

In addition, Equation (11):

$$
b=\frac{-\frac{L_{s}^{\prime}}{P} \Delta T_{e m}+\left(\psi_{s q} E_{d}-\psi_{s d} E_{q}\right) T_{s}}{\left(L_{s}^{\prime} i_{s d}-\psi_{s d}\right)}
$$

Equation (9) is the locus of the final points of the flux vector $\overrightarrow{\psi_{s}^{*}}$ corresponding to the torque change $\Delta T_{e m}$, as depicted in Figure 4 . The same figure shows a circumference with the radius $\psi_{\text {ref }}$, which is the reference flux value described by Equation (12):

$$
\psi_{s d}^{* 2}+\psi_{s q}^{* 2}=\psi_{r e f}^{2}
$$




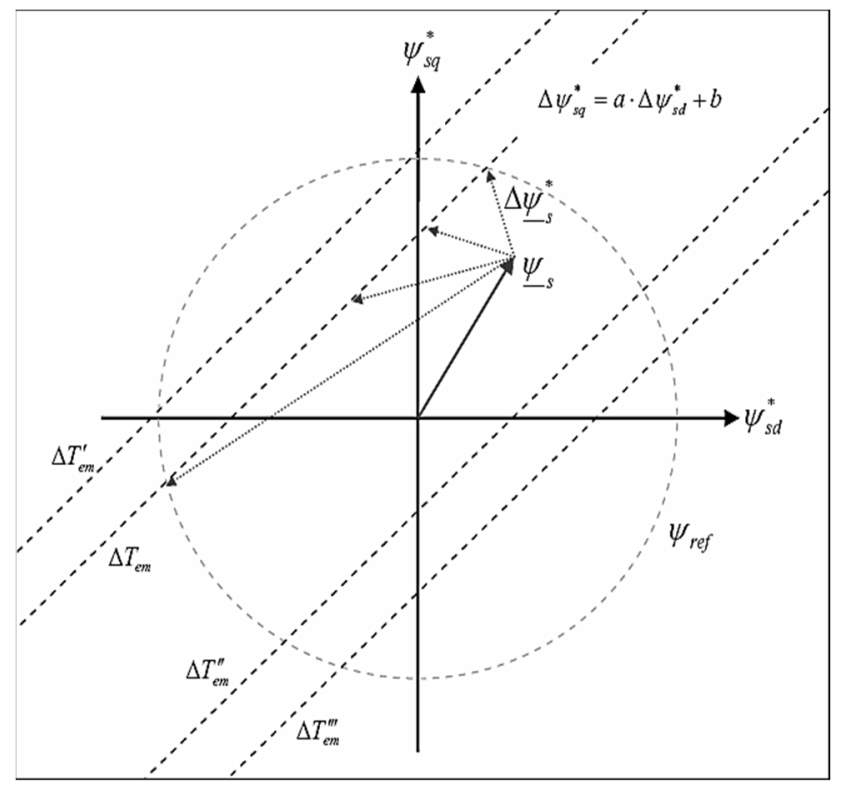

Figure 4. The locus of the final points of the flux vector $\overrightarrow{\psi_{s}^{*}}$ corresponding to the torque change $\Delta T_{e m}$.

The intersection of the line (9) with the circle (12) is a quadratic equation with solutions of Equation (13):

$$
\psi_{s d}^{*}=\frac{-b_{1} \pm \sqrt{b_{1}^{2}-4 a_{1} c_{1}}}{2 a_{1}} \text { and } \psi_{s q}^{*}=\psi_{s q}+a\left(\psi_{s d}^{*}-\psi_{s d}\right)+b
$$

where

$$
\begin{gathered}
a_{1}=\left(1+a^{2}\right), b_{1}=2 a\left(\psi_{s q}-a \psi_{s d}+b\right) \\
\text { and } c_{1}=\left(\psi_{s q}+b\right)^{2}+a^{2} \psi_{s d}^{2}-2 a\left(\psi_{s q}+b\right)-\psi_{r e f}^{2}
\end{gathered}
$$

$\overrightarrow{\psi_{s}^{*}}$ determines the flux change corresponding to the torque change $\Delta T_{e m}$, leading, at the same time, the magnitude of the flux vector to its reference value $\psi_{\text {ref }}$.

Equation (13) gives two solutions corresponding to two different final points of the flux vector: since the flux change rate is proportional to the applied voltage $\vec{V}$, the final point $\overrightarrow{\psi_{s}^{*}}$ nearer to $\overrightarrow{\psi_{s}}$ will be selected because it will correspond to a lower value of the $\vec{V}$ applied.

In transient conditions, it is possible that the requested torque change $\Delta T_{e m}$ should be as such to shift the line outside the circle so that $\Delta=b_{1}^{2}-4 a_{1} c_{1}$ in Equation (13) will be negative: in such a case, a final point $\overrightarrow{\psi_{s}^{*}}$ corresponding to the intersection of one of the two lines tangent to the circle nearer to $\vec{\psi}_{s}$ will be selected, as depicted in Figure 5. 


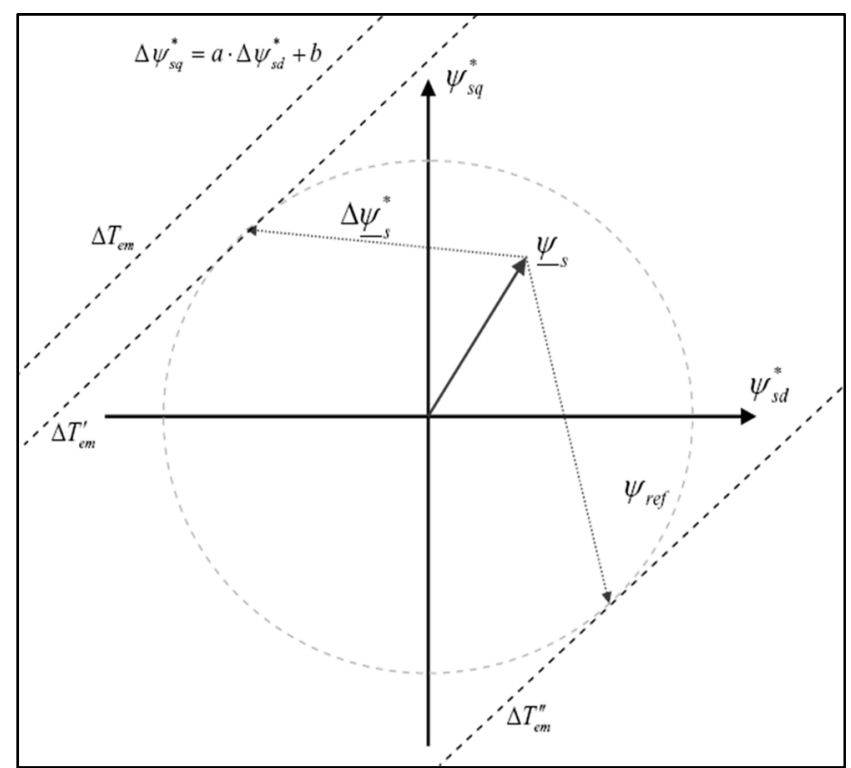

Figure 5. Condition with $\Delta T_{e m}$ torque request such that $\Delta<0$.

Equating $\Delta=0$ and solving with respect to $b$ yields

$$
b^{\prime}, b^{\prime \prime}=-\psi_{s q}+a \psi_{s d} \pm \sqrt{1+a^{2}} \psi_{r e f}
$$

where one of the two values among $b^{\prime}$ and $b^{\prime \prime}$ nearest to $b$ will be the new value of $b$, corresponding to the tangent line nearer to the original one and related to a new torque change $\Delta T_{e m}$.

At this point, the flux change $\Delta \overrightarrow{\psi_{s}^{*}}$ is determined, corresponding to the torque change $\Delta T_{e m}$ over the period $T_{s}$. As observable in Figure $6, \Delta \overrightarrow{\psi_{s}^{*}}$ causes an angle displacement $\gamma$ of the flux vector, which corresponds to a mean electrical angular speed value $\omega_{e}$ over the period

$$
\omega_{e}=2 \pi f_{e}=\frac{\gamma}{T_{s}}
$$

with $f_{e}$ fundamental supply frequency. A synchronous PWM modulation takes place when $m_{f}$, defined by Equation (17):

$$
m_{f}=\frac{f_{s}}{f_{e}}
$$

assumes an integer value, where $f_{s}$ is the PWM frequency. In SVPWM (Space Vector Pulse Width Modulation), $f_{s}$ is such that:

$$
f_{s}=\frac{1}{2 T_{s}}
$$

so that, substituting into Equation (16):

$$
\omega_{e} T_{s}=\gamma=2 \pi f_{e} \frac{1}{2 f_{s}}=\frac{\pi}{\frac{f_{s}}{f_{e}}}=\frac{\pi}{m_{f}}
$$




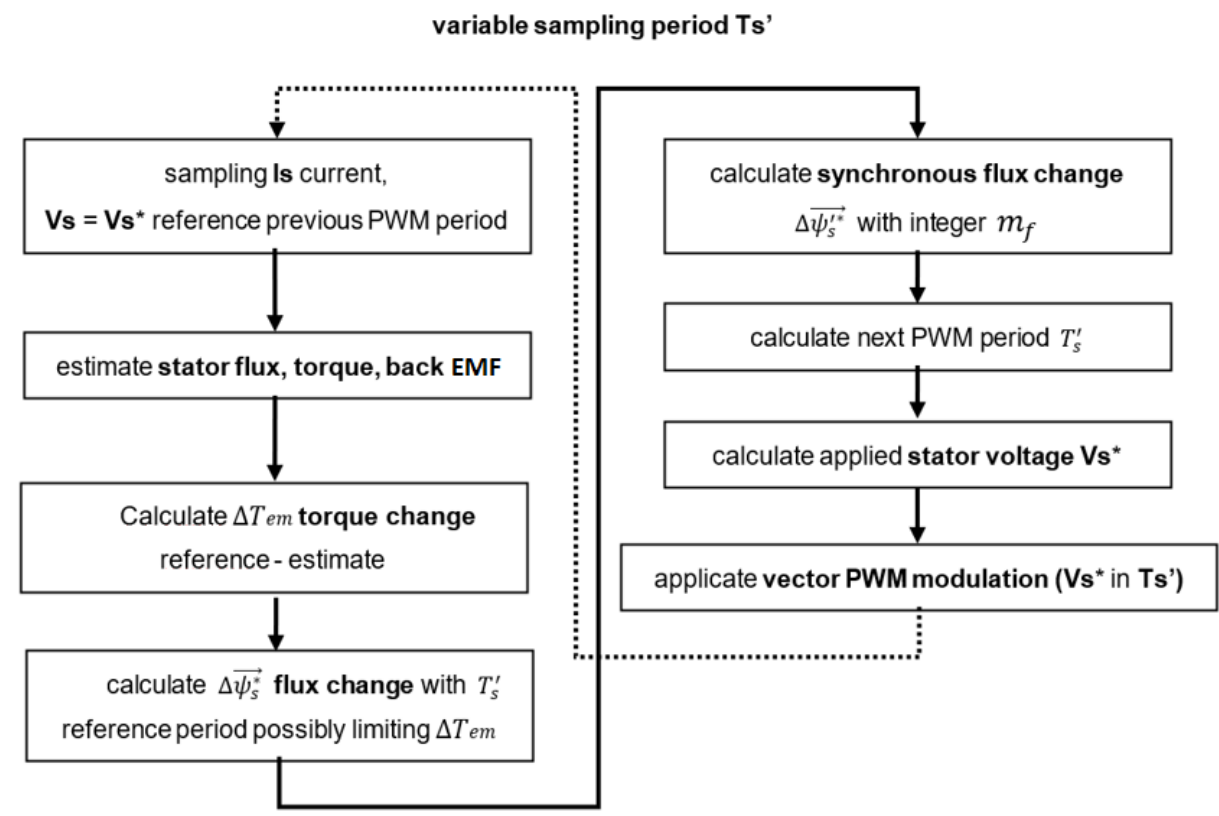

Figure 6. A flowchart of synchronous direct torque control scheme.

The synchronicity condition requires an angle displacement $\gamma$ assuming a new value $\gamma^{\prime}=\pi / m_{f}$ for an integer $m_{f}$ value that is nearest as possible to $\gamma$. This can be obtained by calculating $m_{f}$ from Equation (19), approximating it to the nearest integer value, and finally obtaining $\gamma^{\prime}$ from Equation (19) again. With the new angle change $\gamma^{\prime}$, it is possible to define the definitive flux change $\Delta \overrightarrow{\psi_{s}^{\prime *}}$ :

$$
\begin{aligned}
& \Delta \psi_{s d}^{\prime *}=\psi_{r e f} \cos \left(\arg \left(\vec{\psi}_{s}\right)+\gamma^{\prime}\right)-\psi_{s d} \\
& \Delta \psi_{s q}^{\prime *}=\psi_{r e f} \sin \left(\arg \left(\vec{\psi}_{s}\right)+\gamma^{\prime}\right)-\psi_{s q}
\end{aligned}
$$

In order to maintain the torque change $\Delta T_{e m}$ with the synchronous flux change $\Delta \overrightarrow{\psi_{s}^{\prime *}}$, it is necessary to recalculate a new PWM period $T_{S}^{\prime}$ so as to still satisfy Equation (7)

$$
T_{s}^{\prime}=\frac{\frac{L_{s}^{\prime}}{P} \Delta T_{e m}-L_{s}^{\prime}\left(\Delta \psi_{s d}^{\prime *} i_{s q}-\Delta \psi_{s d}^{\prime *} i_{s q}\right)-\left(\psi_{s d} \Delta \psi_{s q}^{\prime *}-\psi_{s q} \Delta \psi_{s d}^{\prime *}\right)}{\psi_{s q} E_{d}-\psi_{s d} E_{q}}
$$

Here, it is important to observe that $T_{S}$ can be viewed as a reference time value: the synchronous modulation requires a variable SVPWM time period $T_{S}^{\prime}$ to be adjusted time by time in the function of the synchronicity added constraint. The reference voltage $\vec{V}^{*}$ to be applied to the stator inductance derives from $\Delta \overrightarrow{\psi_{s}^{\prime *}}$, as in Equation (23):

$$
\overrightarrow{V^{*}}=\frac{\Delta \overrightarrow{\psi_{s}^{\prime *}}}{T_{S}^{\prime}}
$$

and consequently, considering also the stator resistance drop, the motor command reference voltage $\overrightarrow{V_{S}^{*}}$ is obtained in Equation (24)

$$
\overrightarrow{V_{s}^{*}}=\overrightarrow{V^{*}}-R_{s} \overrightarrow{i_{s}}
$$




\section{Control Scheme Simulation and Results}

The control algorithm theory developed in the previous chapter and outlined in the flowchart of Figure 6 has been implemented in Matlab-Simulink and simulated in the SVPWM two-level inverter-fed induction motor drive system of Figure 7. The parameters of the machine used in the study are given in Table 1. A viscous friction load, having equation $T_{\text {load }}=K\left|\omega_{m}\right| \omega_{m}$, has been connected to the motor shaft. Through the adjustment of $\mathrm{K}$, it has been possible to impose the desired load torque amount at the desired speed.

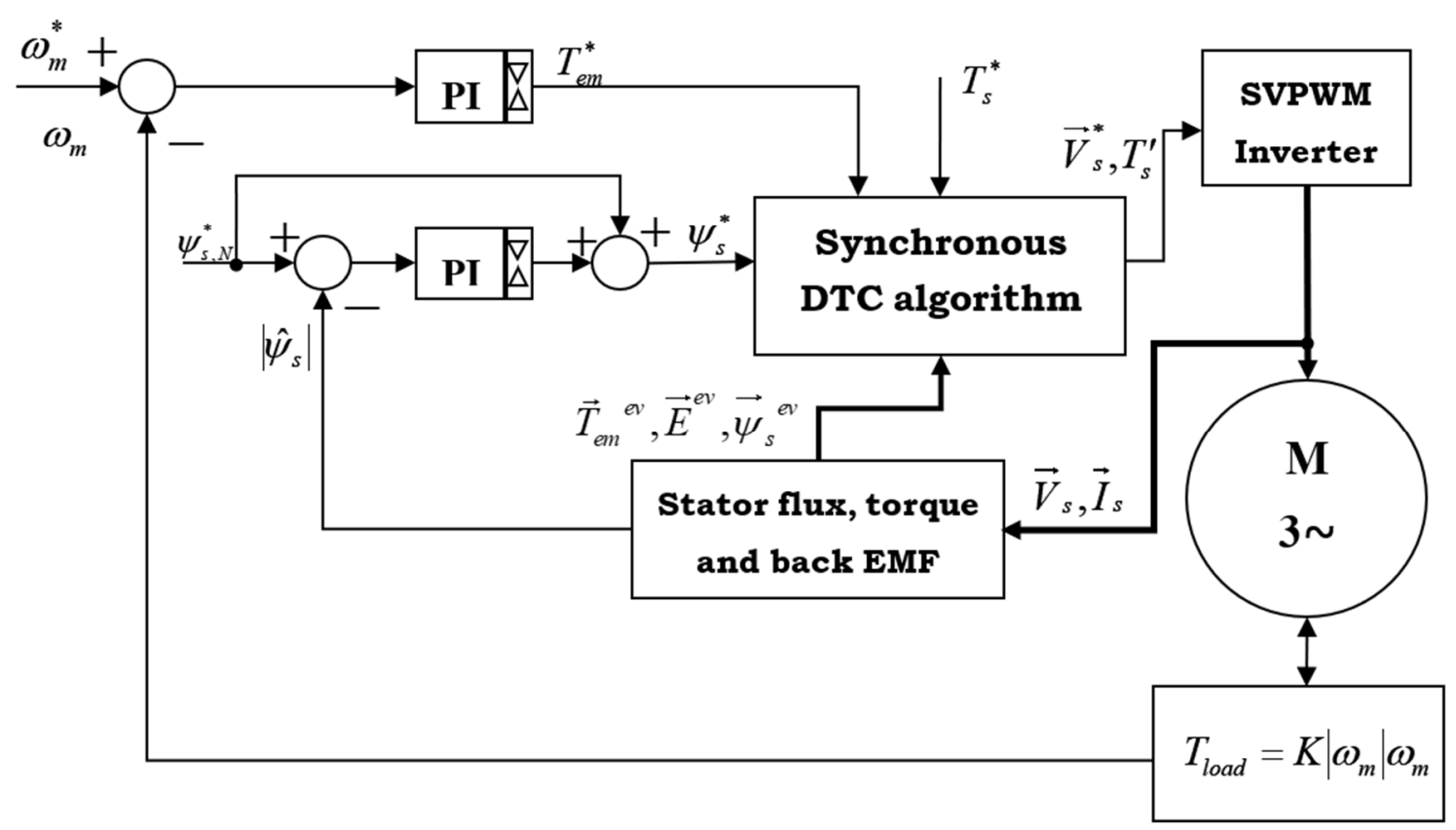

Figure 7. The simulated drive system with synchronous DTC scheme.

Table 1. Motor Data.

\begin{tabular}{cc}
\hline Parameter & Value \\
\hline Rated output power & $110 \mathrm{~kW}$ \\
Rated phase voltage RMS & $380 \mathrm{~V}(\Delta)$ \\
Pole pairs & 3 \\
Rated speed & $979 \mathrm{rpm}$ \\
Rated torque & $1074 \mathrm{Nm}$ \\
Inertia & $1.56 \mathrm{~kg} \mathrm{~m}^{2}$ \\
Rated slip & 0.0209 \\
Stator resistance & $54 \mathrm{~m} \Omega$ \\
Rotor resistance & $62 \mathrm{~m} \Omega$ \\
Stator leakage inductance & $0.8 \mathrm{mH}$ \\
Rotor leakage inductance & $0.5 \mathrm{mH}$ \\
Magnetizing inductance & $7.2 \mathrm{mH}$ \\
\hline
\end{tabular}

The synchronous DTC algorithm needs the estimation of the two-stator flux $\vec{\psi}_{s}^{e v}$ and back EMF $\vec{E}$ vectors and of the mechanical torque ${\overrightarrow{T_{e m}}}^{e v}$ : these quantities are evaluated through Equations (25) and (26)

$$
\begin{gathered}
\vec{\psi}_{s}^{e v}=\int\left(\overrightarrow{V_{s}}-R_{s} \overrightarrow{i_{s}}\right) d \tau, \\
{\overrightarrow{T_{e m}}}^{e v}=P\left(\psi_{s d}{ }^{e v} i_{s q}-\psi_{s q}{ }^{e v} i_{s d}\right)
\end{gathered}
$$

The back EMF is estimated through Equation (5). The trial has been carried out with a speed reference value $\omega_{m}{ }^{*}=0.5 \omega_{n}, \omega_{n}$ rated speed, adjusting K such as to load the motor 
with the rated torque $\left(T_{\text {load }}=1074 \mathrm{Nm}\right)$ at the reference speed. The reference updating PWM period has been set to $T_{s}{ }^{*}=0.001 \mathrm{~s}$. Since the PWM duty cycle is updated twice per switching period, the actual switching frequency of the inverter is $f_{s}=1 / 2 T_{s}{ }^{*}=500 \mathrm{~Hz}$, which corresponds to a reference switching period of $0.002 \mathrm{~s}$. The reference torque was limited to 1.5 times the rated torque of the motor.

In Figures 8 and 9, it is possible to observe the electromagnetic torque and the mechanical speed of the motor, respectively, for a simulation time period $(0,0.5 \mathrm{~s})$. The stator flux path in the two-phase reference frame is represented in Figure 10; note that the control manages to keep the flux magnitude close to its reference value of $0.9876 \mathrm{~Wb}$. Figure 11 depicts the d-axis and q-axis stator currents.

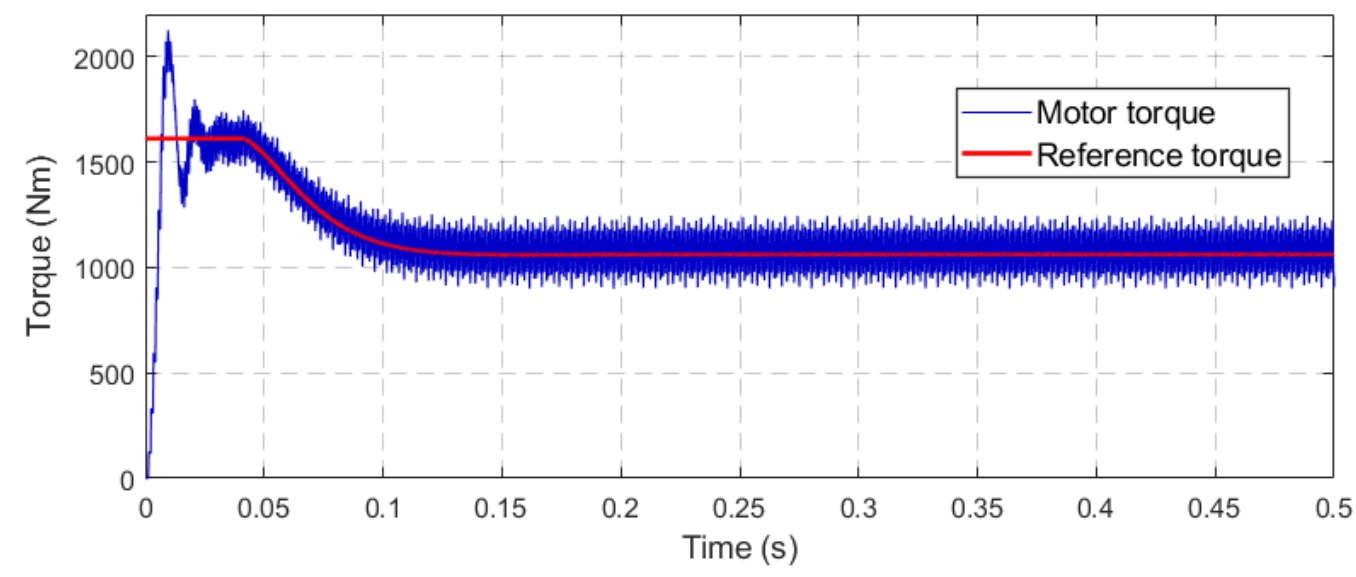

Figure 8. Reference torque and measured torque, $(0,0.5 \mathrm{~s})$.

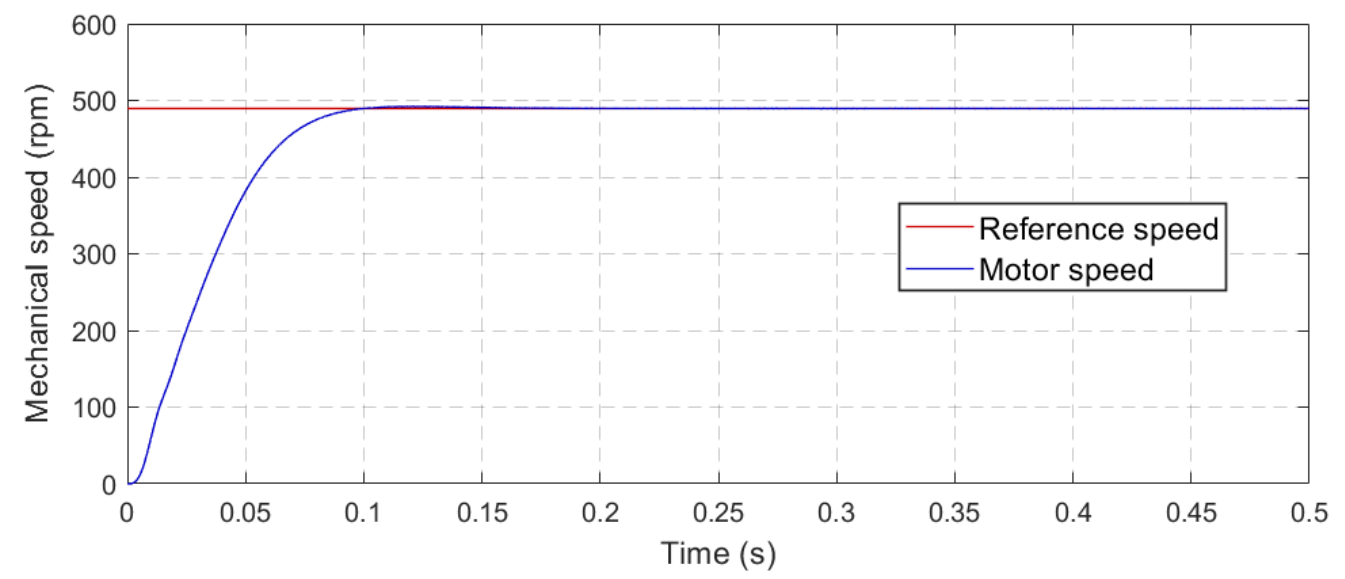

Figure 9. Reference speed and measured speed, (0, $0.5 \mathrm{~s})$.

The evolution of the calculated PWM period, $T_{s}{ }^{\prime}$ of Equation (22), is represented in Figure 12. It is worth noting that the values of $T_{s}{ }^{\prime}$ are distributed close around the reference value $T_{s}^{*}$.

In Figure 13, it is possible to observe the progress of $m_{f}$ : the mean steady state value is about 20, according to an electrical speed $\omega_{e}=2 \pi \times 25 \mathrm{~Hz}$ and a SVPWM frequency of about $f_{s}=500 \mathrm{~Hz}$. In steady state conditions, it is possible to evaluate the FFT of the developed torque; such analysis, related to the time interval $(0.2 \mathrm{~s}, 0.5 \mathrm{~s})$, yields the amplitude frequency spectrum of Figure 14. Because of the selected amplitude scale, the zero-frequency component, equal to the rated load torque $T_{\text {load }}=1074 \mathrm{Nm}$, is not completely observable. By changing the scale, in Figure 15, it is possible to observe an almost zero harmonic content at frequencies below $350 \mathrm{~Hz}$. 


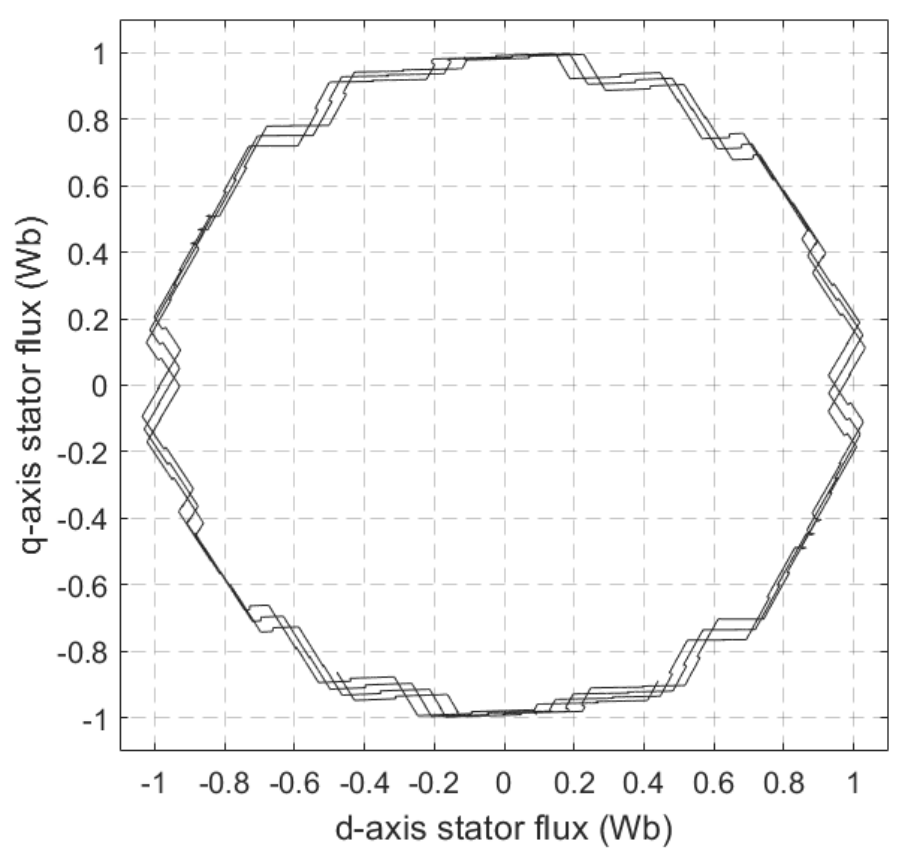

Figure 10. Stator magnetic flux path in the $d-q$-axis reference frame.

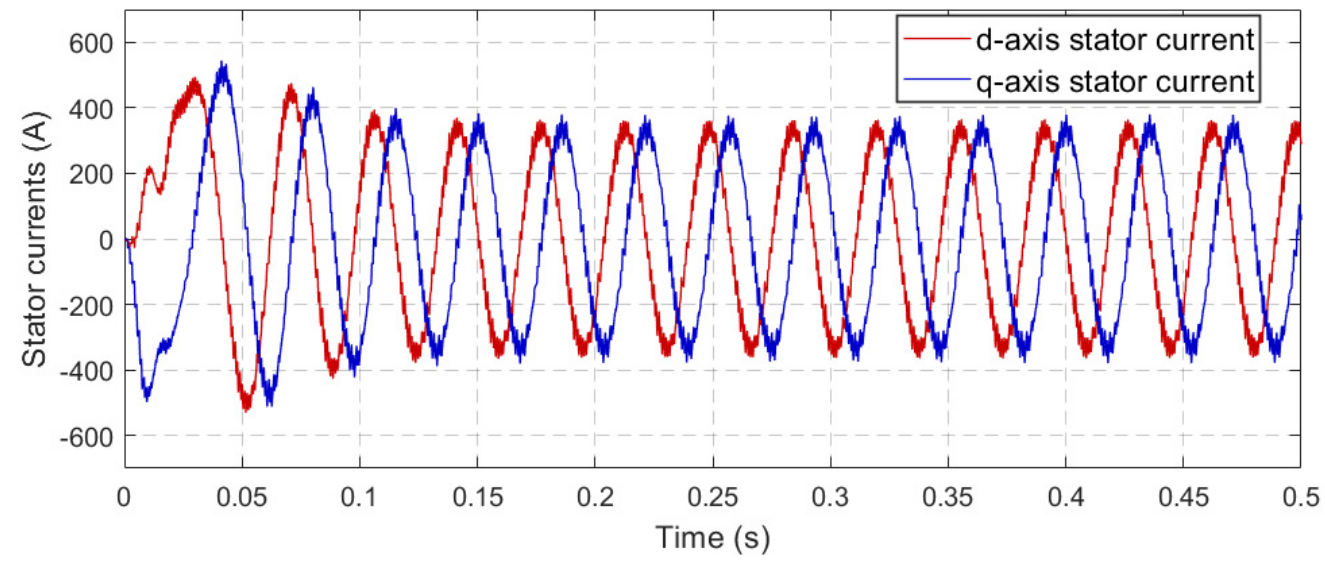

Figure 11. $d$-q-axis stator currents, $(0,0.5 \mathrm{~s})$.

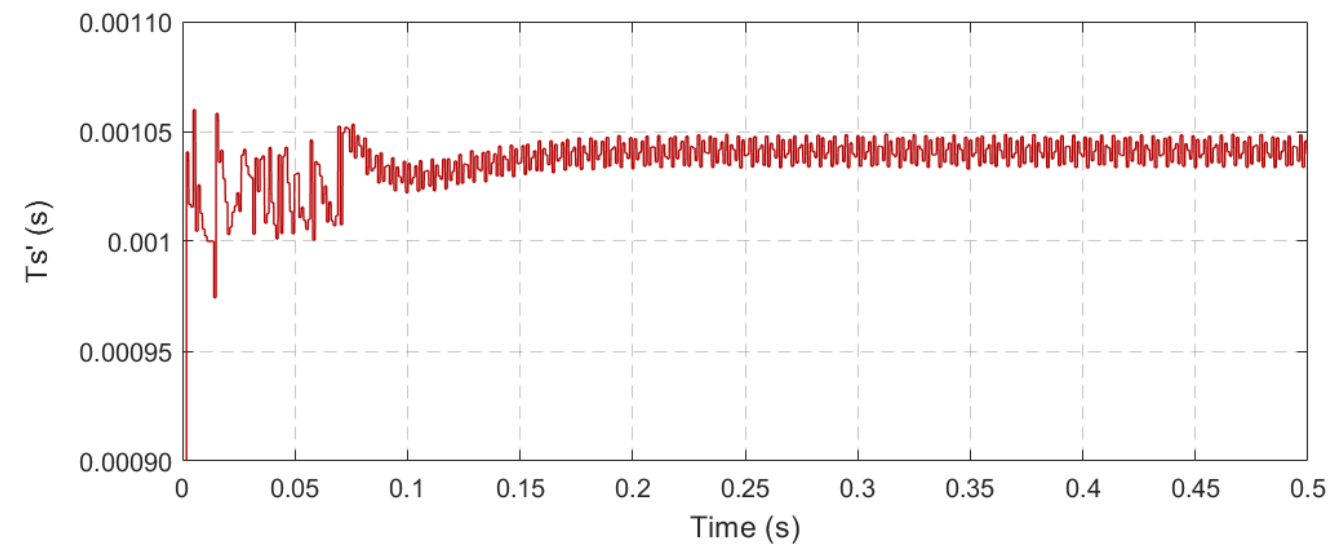

Figure 12. The SVPWM time period $T_{s}{ }^{\prime}$. 


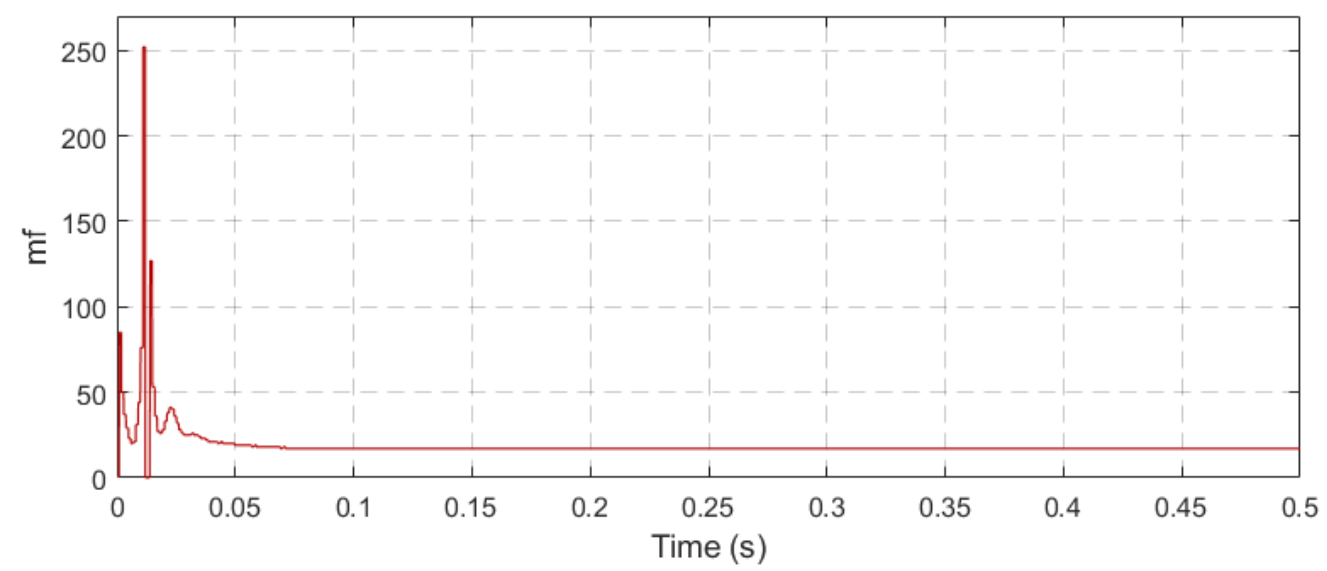

Figure 13. $m_{f}$, ratio of PWM, and fundamental supply frequencies.

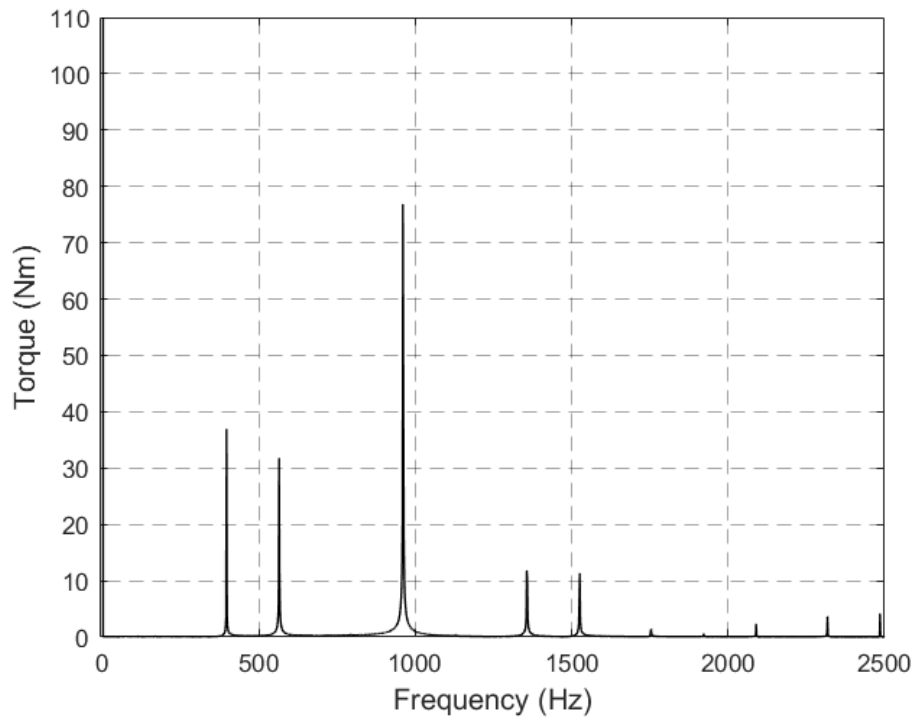

Figure 14. Torque amplitude frequency spectrum, $f \in(0,2.5 \mathrm{kHz})$.

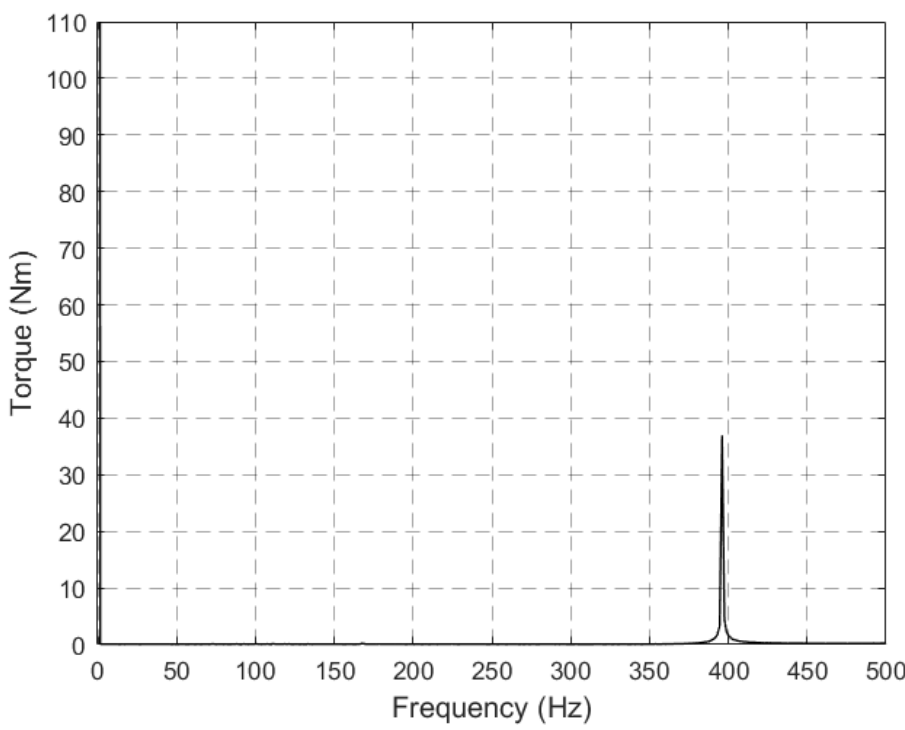

Figure 15. Torque amplitude frequency spectrum, $f \in(0,500 \mathrm{~Hz})$. 


\section{Comparison with the Basic DTC Scheme}

In order to give a comparison of the performance of the synchronous DTC presented with respect to that of a basic DTC scheme, some simulations have been carried out, maintaining the same operating conditions for the two schemes with respect to mechanical speed, load torque, and branch switch inverter frequency. The mean switching frequency of a basic DTC scheme has been matched in value to that of the synchronous DTC by adjusting the amplitudes of the hysteresis bands of flux and torque comparators present in the control scheme. A mean branch switching frequency of $\mathrm{f}_{\mathrm{s}} \approx 500 \mathrm{~Hz}$, equal to that of the synchronous scheme, has been obtained. The torque frequency spectrum obtained with the basic DTC scheme is represented in Figures 16 and 17, respectively, with the same axis scale of Figures 14 and 15. The comparison between Figures 15 and 17 reveals a superior quality of the low-frequency harmonic content in the developed steady-state torque generated by the synchronous DTC scheme. Indeed, several torque sub-harmonics can be observed in the asynchronous DTC spectrum at frequencies below $350 \mathrm{~Hz}$, while they were totally absent in the synchronous case.

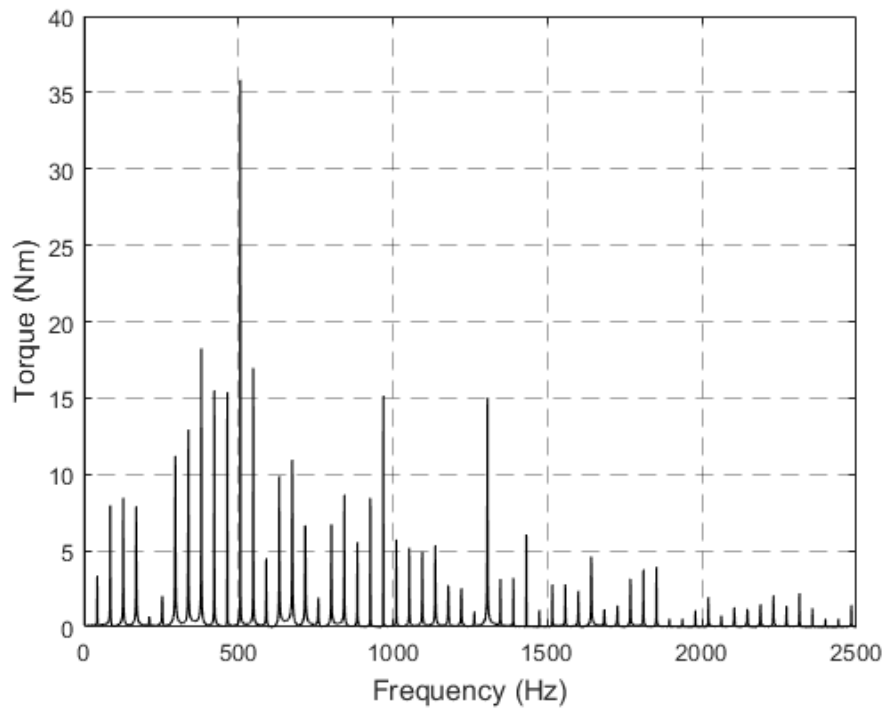

Figure 16. The torque amplitude frequency spectrum, basic DTC scheme, $f \in(0,2.5 \mathrm{kHz})$.

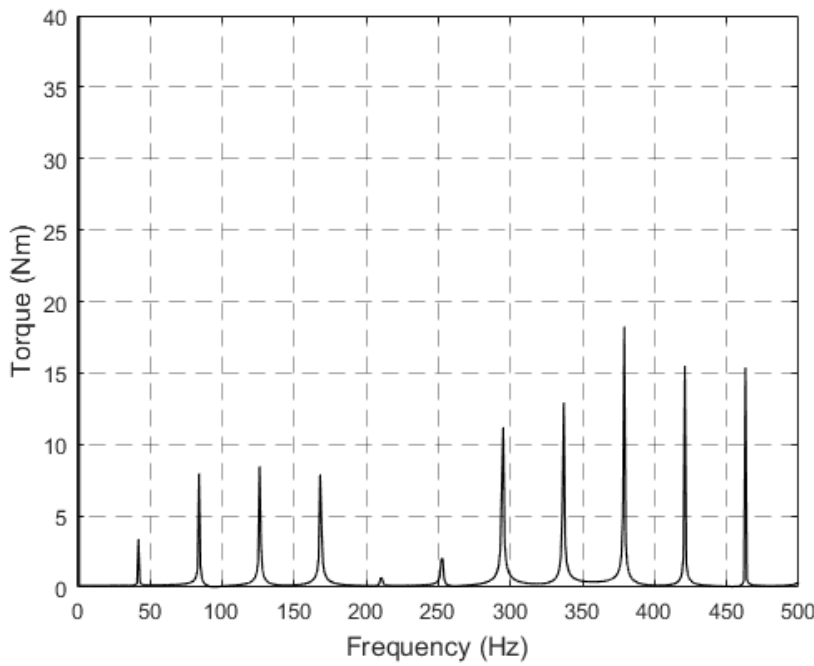

Figure 17. The torque amplitude frequency spectrum, basic DTC scheme, $f \in(0,500 \mathrm{~Hz})$. $\omega_{m}^{*}=0.5 \omega_{n}$. 
In Figures 18 and 19, it is possible to observe, respectively, the steady-state torque spectrums (suitably scaled) obtained with the basic and the synchronous schemes, with another two simulations, carried out with the following conditions: $\omega_{m}{ }^{*}=0.8 \omega_{N}$ reference speed; $T_{\text {load }}=1074 \mathrm{Nm}$ load torque; all other parameters unchanged respect to the previous trials. It is possible to observe again a clearly better performance of the synchronous DTC approach in terms of minor torque low-frequency spectrum content.

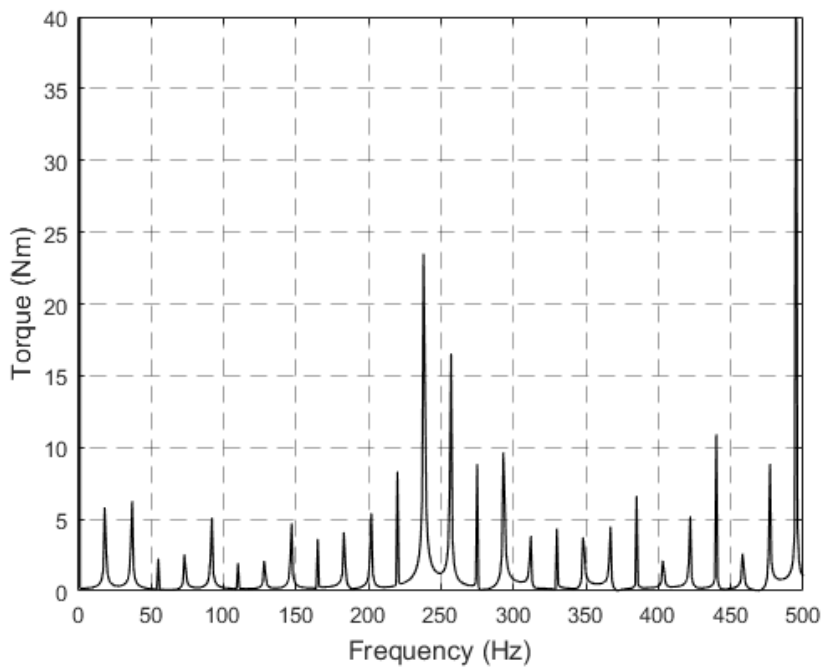

Figure 18. The torque amplitude frequency spectrum, basic DTC scheme, $f \in[0,500 \mathrm{~Hz}]$. $\omega_{m}^{*}=0.8 \omega_{N}$.

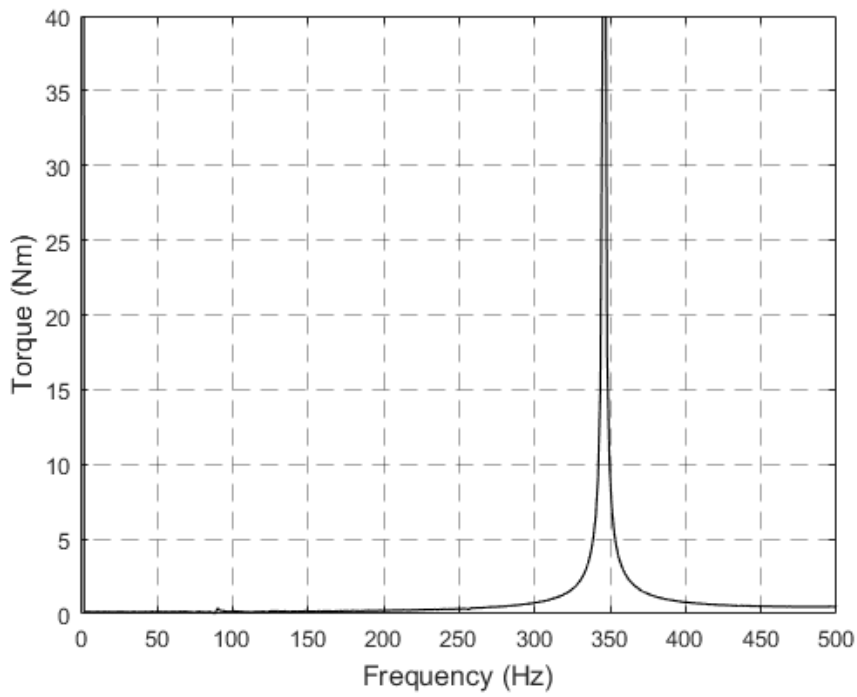

Figure 19. The torque amplitude frequency spectrum, synchronous DTC scheme, $f \in[0,500 \mathrm{~Hz}]$. $\omega_{m}^{*}=0.8 \omega_{N}$.

\section{Load Torque Step}

To test the robustness of the proposed algorithm, another simulation was carried out. The motor was first started setting the reference speed to $\omega_{m}{ }^{*}=0.5 \omega_{N}$ with no load, then a rated load torque step $\left(T_{\text {load }}=1074 \mathrm{Nm}\right)$ was applied at $t=0.2 \mathrm{~s}$. As can be seen from the simulation results, the synchronous DTC algorithm performed well, as the speed returned to its reference value after a short transient. Figures 20 and 21 show the electromagnetic torque and the mechanical speed of the motor, respectively. Please note that the reference torque in Figure 20 is the output of the speed regulator. Figure 22 shows the stator current, while the progress of $m_{f}$ can be observed in Figure 23. 


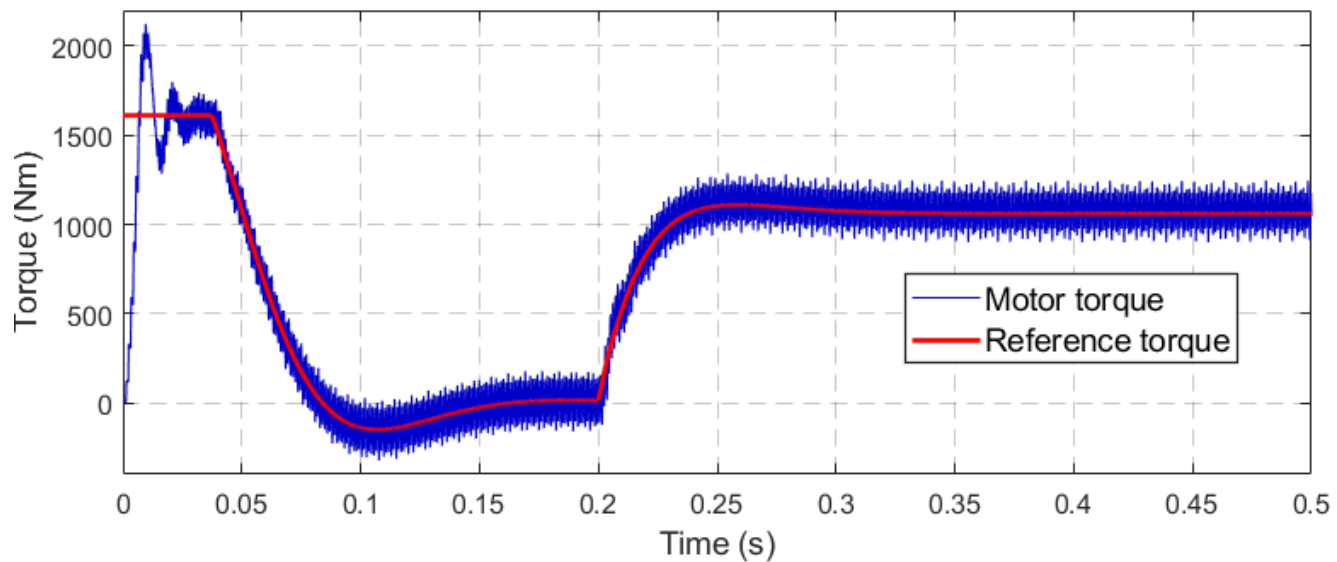

Figure 20. Reference torque and measured torque before and after a rated load torque step is applied at $t=0.2 \mathrm{~s}$.

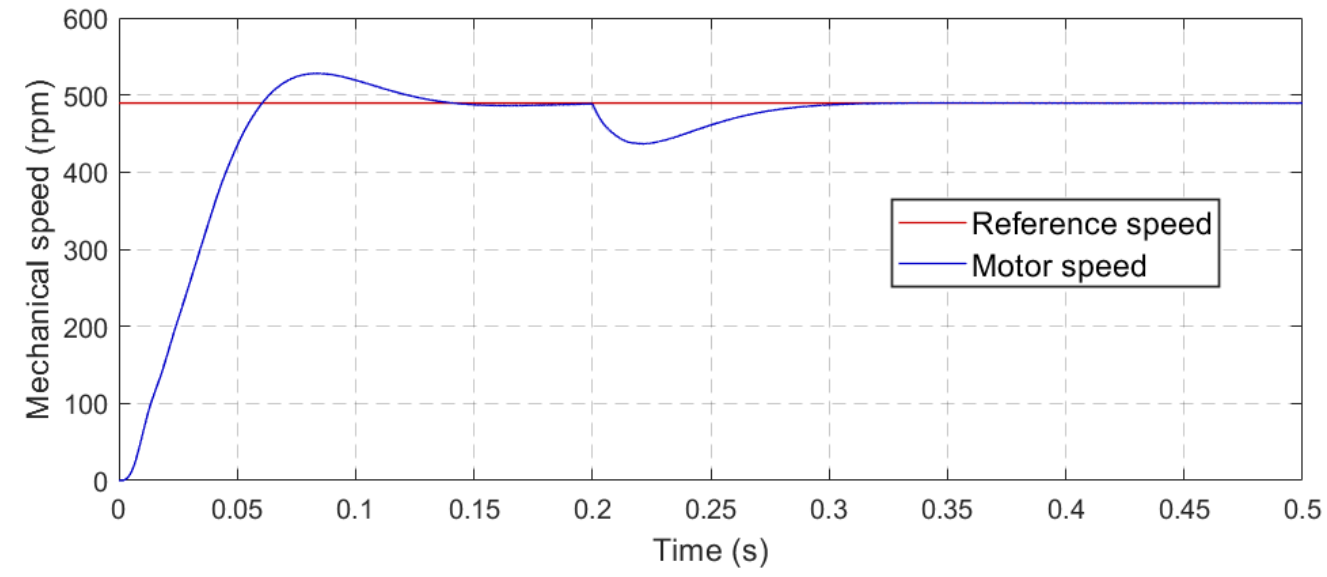

Figure 21. Reference speed and measured speed before and after a rated load torque step is applied at $t=0.2 \mathrm{~s}$.

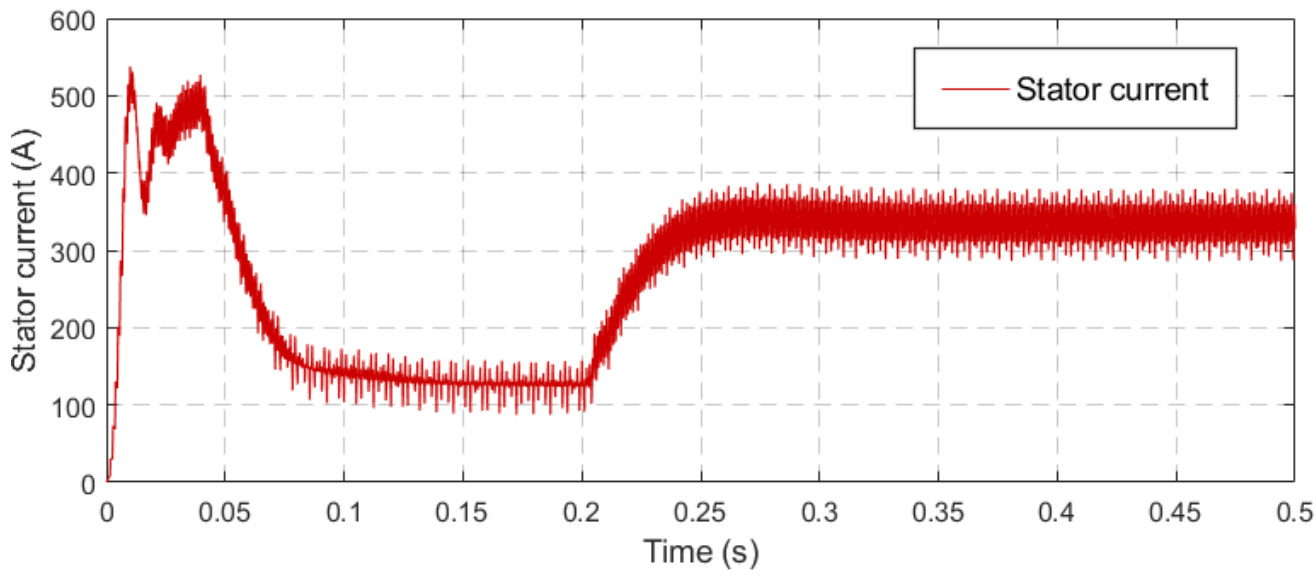

Figure 22. The stator current before and after a rated load torque step is applied at $t=0.2 \mathrm{~s}$. 


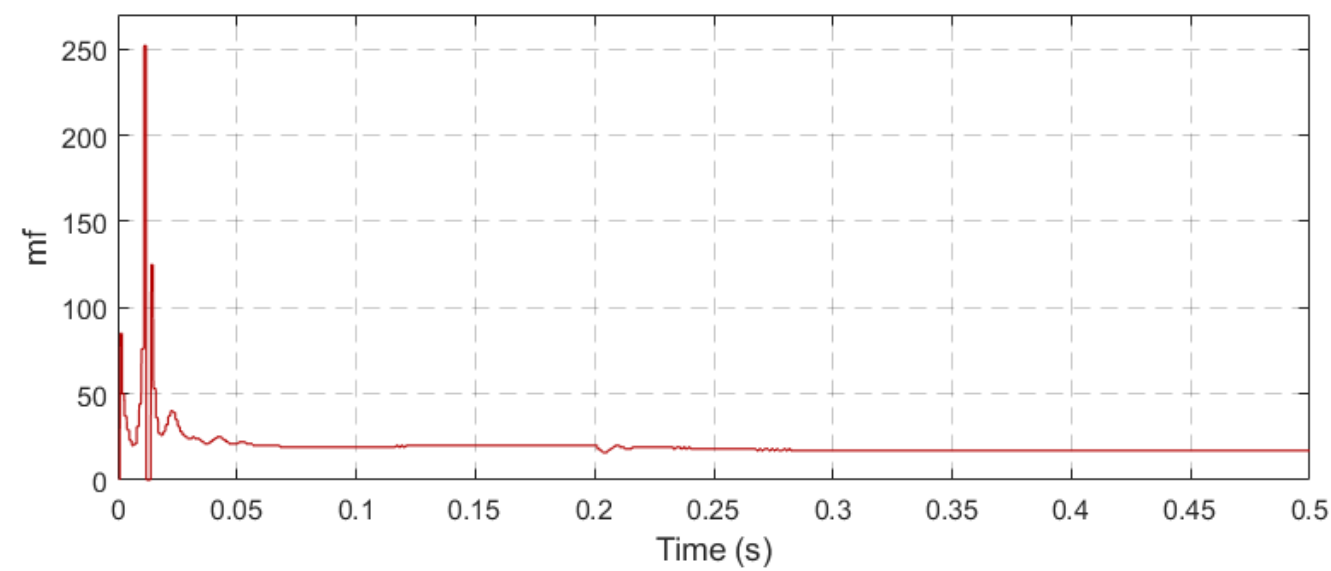

Figure 23. $m_{f}$, ratio of PWM, and fundamental supply frequencies before and after a rated load torque step is applied at $t=0.2 \mathrm{~s}$.

\section{Conclusions}

In this paper, an induction motor direct torque control with synchronous PWM has been presented. Starting from the machine equations and the equivalent stator circuit, a DTC algorithm has been developed, in which an integer ratio between the SVPWM switching frequency and the fundamental supply frequency has been imposed.

The synchronicity condition, represented by the integer ratio of the above-mentioned two frequencies, can be imposed by controlling the evolution of stator flux vector not only in modulus, as in a usual DTC flux loop, but also in phase.

By estimating the back EMF behind the transient inductance, the stator flux vector and the stator current, predicting the change in torque and flux associated with a determined stator voltage command is possible. The flux vector angle change over the single PWM period should assume an integer fraction of $\pi$ rad: this added constraint requires a variable PWM period.

The synchronicity condition, so achieved, is strongly desired in order to minimize the low-frequency harmonic content of the developed torque because low-frequency torque components (typically less than a hundred $\mathrm{Hz}$ ) cannot be well filtered by the equivalent motor low pass transfer function and hence may originate troubles such as mechanical chatter and resonance.

From the developed theory, a control algorithm has been worked out, which has been implemented and simulated in a two-level SVPWM inverter-fed induction motor drive system. The simulation results have been compared in equal conditions of reference speed, load torque, and switches mean frequency, with those obtained with the basic DTC scheme. From the comparison, a superior performance of the novel synchronous DTC scheme has emerged in terms of a much lower steady-state torque low-frequency harmonic content.

The control proposed in this paper will be tested on an experimental test bench in future works.

Author Contributions: Conceptualization, G.M., M.M. and L.V.; data curation, M.P.; formal analysis, M.M., M.P. and L.V.; investigation, L.V.; Methodology, Alessandro Benevieri, G.M. and M.P.; software, Alessandro Benevieri, G.M. and M.P.; supervision, M.M.; writing-original draft, A.B. and G.M.; writing-review and editing, M.M. All authors have read and agreed to the published version of the manuscript.

Funding: This research received no external funding.

Institutional Review Board Statement: Not applicable.

Informed Consent Statement: Not applicable.

Conflicts of Interest: The authors declare no conflict of interest. 


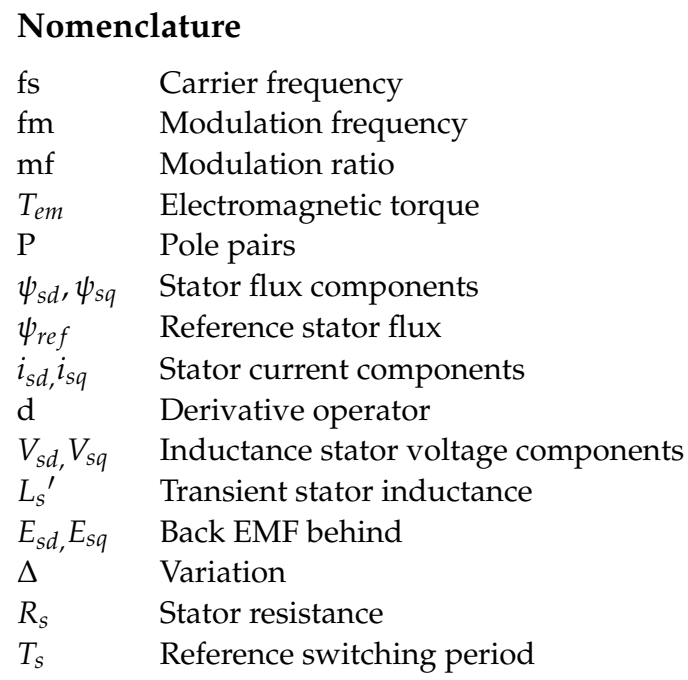

\section{References}

1. Baader, U.; Depenbrock, M.; Gierse, G. Direct Self Control (DSC) of inverter fed induction machine, a basis for speed control without speed measurement. IEEE Trans. Ind. Appl. 1986, 28, 581-588. [CrossRef]

2. Takahashi, I.; Noguchi, F. A new quick response and high efficiency control strategy of an induction machine. IEEE Trans. Ind. Appl. 1986, 22, 820-827. [CrossRef]

3. Cheok, A.D.; Hoon, P.H. A new torque control method for switched reluctance motor drives. In Proceedings of the 2000 26th Annual Conference of the IEEE Industrial Electronics Society. IECON 2000, 2000 IEEE International Conference on Industrial Electronics, Control and Instrumentation. 21st Century Technologies, Nagoya, Japan, 22-28 October 2000.

4. Vas, P. Sensorless Vector and Direct Torque Control; Oxford Science Publications: Oxford, UK, 1998.

5. Kang, J.K.; Sul, S.K. Analysis and prediction of inverter switching frequency in direct torque control of induction machine based on hysteresis bands and machine parameters. IEEE Trans. Ind. Electron. 2001, 48, 545-553. [CrossRef]

6. Wang, F.; Zhang, Z.; Mei, X.; Rodríguez, J.; Kennel, R. Advanced Control Strategies of Induction Machine: Field Oriented Control, Direct Torque Control and Model Predictive Control. Energies 2018, 11, 120. [CrossRef]

7. Karlovsky, P.; Lettl, J. Induction Motor Drive Direct Torque Control and Predictive Torque Control Comparison Based on Switching Pattern Analysis. Energies 2018, 11, 1793. [CrossRef]

8. Nikzad, M.R.; Asaei, B.; Ahmadi, S.O. Discrete Duty-Cycle-Control Method for Direct Torque Control of Induction Motor Drives With Model Predictive Solution. IEEE Trans. Power Electron. 2018, 33, 2317-2329. [CrossRef]

9. Habibullah, M.; Lu, D.D.; Xiao, D.; Rahman, M.F. A Simplified Finite-State Predictive Direct Torque Control for Induction Motor Drive. IEEE Trans. Ind. Electron. 2016, 63, 3964-3975. [CrossRef]

10. Kazmierkowski, M.P.; Kasprowicz, A. Improved direct torque and flux vector control of PWM inverter-fed induction motor drives. IEEE Trans. Ind. Electron. 1995, 42, 334-350. [CrossRef]

11. Ajlan, A.; Rumzi, N.; Idris, N.; Lee, S.S. Minimization of torque ripple in direct torque control of induction motor at low speed. In Proceedings of the 2016 IEEE International Conference on Power and Energy (PECon), Melaka, Malaysia, 28-29 November 2016; pp. 222-227.

12. Zhu, H. Optimizing DTC in case-based development with parametric modeling tools. In Proceedings of the 2017 IEEE International Systems Engineering Symposium (ISSE), Vienna, Austria, 11-13 October 2017; pp. 1-4.

13. Noguchi, T.; Yamamoto, M.; Kondo, S.; Takahashi, I. High frequency switching operation of PWM inverter for direct torque control of induction motor. In Proceedings of the IAS ‘97. Conference Record of the 1997 IEEE Industry Applications Conference Thirty-Second IAS Annual Meeting, New Orleans, LA, USA, 5-9 October 1997; pp. 775-780.

14. Lovati, V.; Marchesoni, M.; Oberti, M.; Segarich, P. A microcontroller-based sensorless stator flux-oriented asynchronous motor drive for traction applications. IEEE Trans. Power Electron. 1998, 13, 777-785. [CrossRef]

15. Telford, D.; Dunnigan, M.W.; Williams, B.W. A novel torque-ripple reduction strategy for direct torque control [of induction motor]. IEEE Trans. Ind. Electron. 2001, 48, 867-870. [CrossRef]

16. Casadei, D.; Profumo, F.; Serra, G.; Tani, A. FOC and DTC: Two viable schemes for induction motors torque control. IEEE Trans. Power Electron. 2002, 17, 779-787. [CrossRef]

17. Farajpour, Y.; Alzayed, M.; Chaoui, H.; Kelouwani, S. A Novel Switching Table for a Modified Three-Level Inverter-Fed DTC Drive with Torque and Flux Ripple Minimization. Energies 2020, 13, 4646. [CrossRef]

18. Del Toro Garcia, X.; Arias, A.; Jayne, M.G.; Witting, P.A. Direct Torque Control of Induction Motors Utilizing Three-Level Voltage Source Inverters. IEEE Trans. Ind. Electron. 2008, 55, 956-958. [CrossRef]

19. Naganathan, P.; Srinivas, S. Direct Torque Control Techniques of Three-Level H-Bridge Inverter Fed Induction Motor for Torque Ripple Reduction at Low Speed Operations. IEEE Trans. Ind. Electron. 2020, 67, 8262-8270. [CrossRef] 
20. Zou, B.; Guo, Y.; Xiao, X.; Yang, B.; Wang, X.; Shi, M.; Tu, Y. Performance Improvement of Matrix Converter Direct Torque Control System. Energies 2020, 13, 3247. [CrossRef]

21. Habetler, T.; Profumo, F.; Pastorelli, M.; Tolbert, L.M. Direct torque control of induction machines using space vector modulation. IEEE Trans. Ind. Appl. 1992, 28, 1045-1053. [CrossRef]

22. Krause, P.C.; Wasynczuck, O.; Sudhoff, S.D. Analysis of Electric Machinery; IEEE Press: Piscataway Township, NJ, USA, 1995. 